\title{
Effect of biotin and pantothenic acid on performance and concentrations of avidin-binding substances in blood and milk of lactating dairy cows ${ }^{1}$
}

\author{
Gonzalo Ferreira, ${ }^{2}$ Alston N. Brown, and Christy L. Teets \\ Department of Dairy Science, Virginia Polytechnic Institute and State University, Blacksburg 24061
}

\begin{abstract}
We hypothesized that pantothenic acid reduces the absorption of biotin in lactating dairy cows. Therefore, the objective of this study was to evaluate the plausible interaction between biotin and pantothenic acid on production performance and concentration of avidin-binding substances (ABS), an indicator of biotin concentration, in blood and milk of lactating dairy cows. Eight primiparous and 16 multiparous Holstein cows were assigned to 1 of 4 diet sequences in a replicated $4 \times 4$ Latin square design with 18 -d periods. Cows were housed in a freestall barn and fed once daily $(0730 \mathrm{~h})$ by means of a Calan gate system (American Calan Inc., Northwood, NH). Treatments consisted of a control diet that contained no B-vitamins, a biotin diet that contained $0.87 \mathrm{mg}$ of biotin per kilogram of dry matter (DM), a pantothenic acid diet that contained $21 \mathrm{mg}$ of pantothenic acid per kilogram of DM, and a biotin plus pantothenic acid diet that contained 0.87 $\mathrm{mg}$ of biotin and $21 \mathrm{mg}$ of calcium pantothenic acid per kilogram of DM. Four different concentrates were prepared in a commercial feed mill. These concentrates were mixed with corn silage and grass hay and delivered ad libitum as a total mixed ration. Biotin supplementation did not affect DM intake, milk yield, or milk fat, protein, lactose, and milk-urea-nitrogen concentrations. Fat, protein, and lactose yields were not affected by treatments. The fat-to-protein ratio was $<1$ and similar among all treatments. Biotin supplementation did not increase the concentration of ABS in plasma. The supplementation of pantothenic acid did not affect the concentration of ABS in plasma when either supplemented alone or in combination with biotin. Biotin supplementation increased the concentration of ABS in milk relative to control. Contrary to our hypothesis, the supplementation of pantothenic acid did not decrease the concentration of $\mathrm{ABS}$ in milk relative to the control. When cows were supplemented with both biotin
\end{abstract}

Received March 24, 2015.

Accepted May 15, 2015.

${ }^{1}$ Mention of commercial products in this study is entirely for experimental purposes. No endorsements are herein implied.

${ }^{2}$ Corresponding author: gonf@vt.edu and pantothenic acid, the concentration of ABS in milk was similar to that of cows supplemented with biotin alone. In conclusion, pantothenic acid did not affect the concentrations of ABS in plasma and milk, suggesting that increasing dietary supply of pantothenic acid did not inhibit biotin absorption.

Key words: biotin, pantothenic acid, avidin-binding substance, absorption

\section{INTRODUCTION}

Biotin is a water-soluble vitamin that is synthesized by plants and several microorganisms. Because they cannot synthesize biotin, mammals rely on intake through the diet and on microbial synthesis in the gastrointestinal tract to meet their biotin needs. Biotin supplementation increased milk yield of lactating cows in several studies (Midla et al., 1998; Zimmerly and Weiss, 2001; Majee et al., 2003), although this response has been inconsistent (Fitzgerald et al., 2000; Majee et al., 2003; Rosendo et al., 2004). Fitzgerald et al. (2000) showed that biotin supplementation did not affect milk yield in low-producing cows. Ferreira et al. (2007) showed that biotin supplementation increases milk yield in high-producing, but not in low-producing, dairy cows. Majee et al. (2003) stated that potential negative interactions among B-vitamins may have reduced lactation performance when cows were fed high doses of biotin plus B-vitamins compared with cows fed biotin alone or low doses of biotin plus B-vitamins.

A facilitated mechanism in the brush-border membrane of the enterocytes allows the absorption of biotin against a concentration gradient in the intestine of rats (Said and Redha, 1987), rabbits (Said and Derweesh, 1991), and humans (Said et al., 1987, 1988). This transport is sodium dependent (Said and Redha, 1987; Said et al., 1987, 1988) and greatest under acidic conditions (Said et al., 1988). Biotin absorption through this transporter can be decreased by biotin analogs (Said and Redha, 1987; Said et al., 1987; Said and Derweesh, 1991) and pantothenic acid (Said, 1999), showing that this transporter is not specific for biotin. The activity of the biotin transporter varies depending on the site within the intestine (Said et al., 1988) and on 
biotin status (Said et al., 1989). Using brush-border membrane vesicles, Said et al. (1989) observed that biotin transport increased in biotin-deficient rats and decreased in biotin-supplemented rats. Prasad et al. (1998) transfected placental cDNA that encodes this transporter into uterine cells and observed that the transport of biotin into these cells was substantially increased. This increase was inhibited by pantothenic acid and lipoic acid, but not by myoinositol, showing that the transporter is specific for biotin, pantothenic acid, and lipoic acid. The increased transport of biotin and pantothenic acid was not observed in the absence of sodium, implying sodium dependence. Prasad et al. (1998) named this transporter as sodium-dependent multivitamin transporter (SMVT).

To our knowledge, the presence of a biotin transporter similar to SMVT in the gastrointestinal tract of dairy cows, or any other ruminant, has not been determined. Chatterjee et al. (1999) showed that the uptake of biotin was inhibited when cells containing transfected intestinal SMVT from rats were incubated with pantothenic acid. Based on the assumption that biotin uptake in dairy cows occurs via a SMVT system, for this study we hypothesized that increasing pantothenic acid supply reduces the absorption of biotin in lactating dairy cows. Therefore, the objective of this study was to evaluate the plausible interaction between biotin and pantothenic acid on production performance and concentration of avidin-binding substances (ABS), an indicator of biotin concentration, in blood and milk of lactating dairy cows.

\section{MATERIALS AND METHODS}

\section{Animals, Housing, and Diets}

All procedures involving animals were approved by the Institutional Animal Care and Use Committee of Virginia Tech. Eight primiparous $(511 \pm 41 \mathrm{~kg}$ of BW and $74 \pm 18$ DIM at the beginning of the experiment) and 16 multiparous Holstein cows $(624 \pm 51 \mathrm{~kg}$ of BW and $94 \pm 33$ DIM at the beginning of the experiment) were assigned to 1 of 4 diet sequences in a replicated $4 \times 4$ Latin square design, with 6 independent squares and 18-d periods.

Cows were housed in a 24-stall pen within a freestall barn. Cows were fed once daily $(0730 \mathrm{~h})$ by means of a Calan gate system (American Calan Inc., Northwood, $\mathrm{NH}$ ). Cows were trained to find their door for a 2 -wk period before the beginning of the study.

Treatments consisted of a basal or control diet that contained no B-vitamins, a biotin diet that contained $0.87 \mathrm{mg}$ of supplemental biotin (Rovimix Biotin 2\%, DSM Nutritional Products Inc., Parsippany, NJ) per kilogram of DM, a pantothenic acid diet that contained $21 \mathrm{mg}$ of supplemental pantothenic acid (Rovimix Calpan, DSM Nutritional Products Inc.) per kilogram of DM, and a biotin plus pantothenic acid diet that contained $0.87 \mathrm{mg}$ of supplemental biotin and $21 \mathrm{mg}$ of supplemental pantothenic acid per kilogram of DM. The basal diet was formulated to meet nutrient requirements (NRC, 2001) for a 630-kg lactating dairy cow producing $42 \mathrm{~kg}$ of milk per day. The concentration of biotin was chosen to supply approximately $20 \mathrm{mg}$ of biotin per day based on a 22.5-kg daily DMI (Zimmerly and Weiss, 2001; Majee et al., 2003; Ferreira et al., 2007). The concentration of pantothenic acid was chosen to supply approximately $475 \mathrm{mg}$ of pantothenic acid per day, which was the lowest dose used by Majee et al. (2003).

Four different concentrates were prepared in a commercial feed mill (Southern States Cooperative, Vinton, VA). These concentrates were mixed with corn silage and grass hay (Table 1) and delivered ad libitum ( $\sim 5 \%$ refusals, as-fed basis) as a TMR. Mixing and delivery was performed using a Calan Data Ranger (American Calan Inc.). The amount of feed offered and refused was measured daily. Cows were milked twice daily (0300 and $1300 \mathrm{~h}$ ), and milk weights were automatically recorded at each milking. The average of the daily milk yields and DMI from d 13 to 18 of each period was used for statistical analysis.

\section{Sample Collection and Analysis}

Composite samples of feed ingredients and feed refused were collected at the end of each period (d 13 to 18). All feed samples were dried in a forced-air oven $\left(55^{\circ} \mathrm{C}\right)$ until a constant weight was reached, and they were ground to pass through a 1-mm screen of a Wiley mill (Thomas Scientific, Swedesboro, NJ). Crude protein concentration was calculated as percent $\mathrm{N} \times 6.25$ after combustion analysis using a Vario El Cube CN analyzer (Elementar Americas Inc., Mount Laurel, NJ). Neutral detergent fiber concentration was determined using the Ankom200 Fiber Analyzer (Ankom Technology, Macedon, NY) with sodium sulfite and $\alpha$-amylase (Ankom Technology). Acid detergent fiber and lignin concentrations were determined sequentially. After determining ADF weights, residues were incubated for 2 $\mathrm{h}$ in $72 \%$ sulfuric acid within a 4 -L jar that was placed in a DaisyII Incubator (Ankom Technology). Starch concentration was determined using the acetate buffer method of Hall (2009) with $\alpha$-amylase from Bacillus licheniformis (FAA, Ankom Technology) and amyloglucosidase from Aspergillus niger (E-AMGDF, Megazyme International, Wicklow, Ireland). Ash concentration 
Table 1. Ingredient and chemical composition of basal diet (DM basis)

\begin{tabular}{|c|c|}
\hline Item, $\%$ & Value \\
\hline Corn silage $^{1}$ & 41.5 \\
\hline Grass hay $^{2}$ & 7.8 \\
\hline Corn grain & 14.9 \\
\hline Soybean meal & 11.8 \\
\hline Soybean hulls & 11.8 \\
\hline Soyplus ${ }^{3}$ & 9.0 \\
\hline Energy Booster $100^{4}$ & 0.8553 \\
\hline Sodium sesquicarbonate & 0.8553 \\
\hline Ground limestone & 0.6414 \\
\hline Salt & 0.5132 \\
\hline Magnesium oxide & 0.1711 \\
\hline Trace mineral premix ${ }^{5}$ & 0.0385 \\
\hline Vitamin $\mathrm{E}^{6}$ & 0.0218 \\
\hline Vitamin ADE premix ${ }^{7}$ & 0.0175 \\
\hline Rumensin $90^{8}$ & 0.0065 \\
\hline Supplemental vitamins ${ }^{9}$ & - \\
\hline DM & 55.1 \\
\hline Ash & 6.6 \\
\hline $\mathrm{CP}$ & 16.2 \\
\hline NDF & 32.2 \\
\hline Forage NDF & 18.6 \\
\hline Starch & 27.6 \\
\hline
\end{tabular}

${ }^{1}$ Corn-silage composition (DM basis): $35.6 \%$ DM; $3.1 \%$ ash; $8.9 \% \mathrm{CP}$; $32.6 \%$ NDF; $18.9 \%$ ADF; $1.4 \%$ ADL; $39.5 \%$ starch.

${ }^{2}$ Grass-hay composition (DM basis): $85.3 \%$ DM; $9.3 \%$ ash; $12.8 \% \mathrm{CP}$; $64.7 \%$ NDF; $41.1 \%$ ADF; 3.3\% ADL; $2.1 \%$ starch.

${ }^{3}$ West Central Cooperative, Ralston, IA.

${ }^{4}$ Milk Specialties Global, Eden Prairie, MN.

${ }^{5}$ Contained 40,000 mg/kg of copper, $30,000 \mathrm{mg} / \mathrm{kg}$ of iron, 16,000 mg/ $\mathrm{kg}$ of zinc, $15,000 \mathrm{mg} / \mathrm{kg}$ of manganese, $1,600 \mathrm{mg} / \mathrm{kg}$ of cobalt, and $3,500 \mathrm{mg} / \mathrm{kg}$ of iodine.

${ }^{6}$ Contained 132,000 IU of vitamin E per kilogram of product.

${ }^{7}$ Contained $26,400 \mathrm{kIU}$ of vitamin A, 8,800 kIU of vitamin D, and 44,000 IU of vitamin E per kilogram of premix.

${ }^{8}$ Contains $200 \mathrm{mg}$ of monensin per gram of product (Elanco Animal Health, Indianapolis, IN).

${ }^{9}$ The control diet contained no supplemental vitamins; the biotin diet contained $0.0043 \%$ (DM basis) of Rovimix Biotin (2\% biotin; DSM Nutritional Products Inc., Parsippany, NJ); the pantothenic acid diet contained $0.0023 \%$ (DM basis) of Rovimix Calpan (92\% pantothenic acid; DSM Nutritional Products Inc.); and the biotin + pantothenic acid diet contained 0.0043 and $0.0023 \%$ of Rovimix Biotin and Rovimix Calpan, respectively.

was determined after burning feed samples in a furnace $\left(3 \mathrm{~h}\right.$ at $\left.550^{\circ} \mathrm{C}\right)$.

Milk samples (a.m. and p.m. milkings) were collected on d 18 for determination of milk fat, protein, lactose, and MUN concentrations with a CombiFoss FT+ Fourier transform infrared analyzer (Foss, Hillerød, Denmark) by United DHIA (Radford, VA). An additional milk sample (a.m. milking) was collected on d 18 to determine the concentration of avidin-binding substances in milk. One blood sample was collected on d 18 (immediately after p.m. milking) by venipuncture of the coccygeal vein, immediately transferred into heparinized tubes, stored in ice, and transferred to the laboratory. Plasma was obtained after centrifugation of blood at 3,000 $\times g$ (using rubber cushions) for $30 \mathrm{~min}$ at $4^{\circ} \mathrm{C}$ and stored at $-20^{\circ} \mathrm{C}$ until ABS analysis.

Concentrations of ABS in skim milk (1:300 dilution for the control diet and pantothenic acid diet, and 1:800 dilution for the biotin diet and biotin plus pantothenic acid diet) and plasma (1:20 dilution) were determined by a single-step competitive enzyme-binding assay (Ridascreen Biotin kit; R-Biopharm GmbH, Darmstadt, Germany) as described by Ferreira et al. (2007).

\section{Statistical Analysis}

One cow was diagnosed with clinical mastitis and therefore removed from the experiment, at the end of period 1. No data were collected for this cow. Another cow showed chronic signs of mastitis during periods 3 and 4. Dry matter intake, milk yield, and milk composition data from this cow were discarded for statistical analysis.

All variables were analyzed using the MIXED procedure of SAS (SAS version 9.3, SAS Institute Inc., Cary, NC). The statistical model included the effects of square (fixed; $\mathrm{df}=5$ ), treatments (fixed; $\mathrm{df}=3$ ), square $\times$ treatment interaction (fixed; $\mathrm{df}=15$ ), period (random; $\mathrm{df}=3$ ), and cow within square (random; $\mathrm{df}$ $=18$ ) and the random residual error. Comparisons between treatment least squares means were tested using the PDIFF option of SAS.

\section{RESULTS}

Biotin supplementation did not affect DMI $(P>$ $0.45)$, milk yield $(P>0.67)$, or milk fat $(P>0.84)$, protein $(P>0.27)$, lactose $(P>0.89)$, and MUN concentrations $(P>0.48$; Table 2$)$. Fat $(P>0.87)$, protein $(P>0.06)$, and lactose $(P>0.24)$ yields were not affected by treatments (Table 2 ). The fat-to-protein ratio was $<1$ and similar among all treatments.

Biotin supplementation did not increase $(P>0.38)$ the concentration of ABS in plasma (Figure 1). The supplementation of pantothenic acid did not affect the concentration of ABS in plasma when either supplemented alone or in combination with biotin.

Biotin supplementation increased the concentration of ABS in milk relative to control $(P<0.03$; Figure 2 ). Contrary to our hypothesis, the supplementation of pantothenic acid did not decrease the concentration of ABS in milk relative to the control $(P>0.99)$. When cows were supplemented with both biotin and pantothenic acid, the concentration of ABS in milk was similar to that of cows supplemented with biotin alone $(P>0.47)$. 


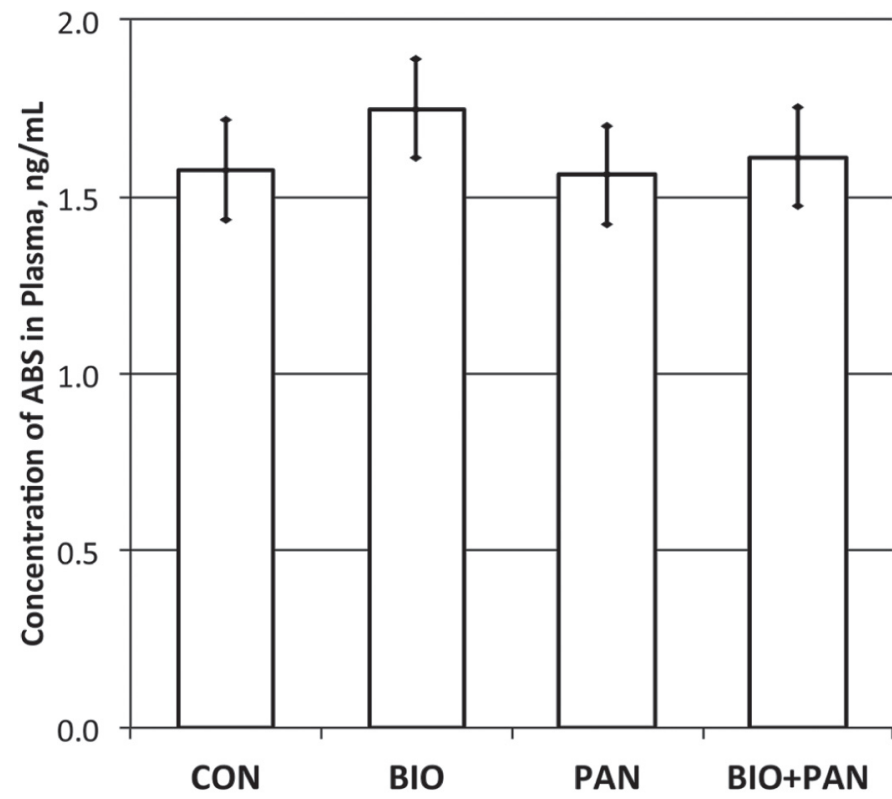

Figure 1. Concentration of avidin-binding substances (ABS) in plasma of lactating dairy cows fed a control diet (CON), a diet supplemented with $0.87 \mathrm{mg}$ of biotin per kilogram of DM (BIO), a diet supplemented with $21 \mathrm{mg}$ of pantothenic acid per kilogram of DM (PAN), or a diet supplemented with $0.87 \mathrm{mg}$ of biotin and $21 \mathrm{mg}$ of pantothenic acid per kilogram of DM (BIO+PAN). Error bars indicate the standard error of the mean $(\mathrm{SEM}=0.14 \mathrm{ng} / \mathrm{mL})$.

\section{DISCUSSION}

Contrary to our expectations, biotin supplementation did not increase milk yield of lactating cows. The reasons for the lack of response in milk yield in this study are not clear. Ferreira et al. (2007) showed that biotin supplementation increases milk yield in highproducing but not in low-producing cows (41.8 and $24.1 \mathrm{~kg} / \mathrm{d}$, respectively). Milk production of control cows from this study (Table 2) was similar to that of high-producing cows reported by Ferreira et al. (2007), and greater than that of cows reported by Majee et al. (2003). Lactation stage in this study was also similar to that of high-producing cows from Ferreira et al. (2007).

A unique observation from this study is that biotin supplementation did not increase the concentration of ABS in plasma (Figure 1). All previous studies that measured it showed that biotin supplementation increases the concentration of ABS in plasma (Table 3). Under the assumption that ABS concentration is an indicator of actual biotin (Ferreira et al., 2007), a similar concentration of biotin in plasma would indicate either that biotin supplementation was not high enough to increase its concentration in plasma, or that the basal concentration of biotin in plasma was higher than typically reported. Because biotin supplementation indeed increased the concentration of ABS in milk (Figure 2),
Table 2. Effect of biotin and pantothenic acid supplementation on production performance and milk composition of lactating dairy cows

\begin{tabular}{lcccccc}
\hline Item & CON & BIO & PAN & BIO+PAN & SEM & $P>$ \\
\hline DMI, kg/d & 21.6 & 21.5 & 21.2 & 21.1 & 0.49 & 0.45 \\
Milk yield, kg/d & 41.9 & 41.9 & 42.1 & 41.1 & 1.41 & 0.67 \\
Fat, \% & 2.83 & 2.79 & 2.88 & 2.90 & 0.19 & 0.84 \\
Protein, \% & 3.01 & 3.07 & 3.03 & 3.04 & 0.06 & 0.27 \\
Lactose, \% & 4.88 & 4.90 & 4.89 & 4.89 & 0.04 & 0.89 \\
Fat, kg/d & 1.18 & 1.18 & 1.22 & 1.18 & 0.08 & 0.87 \\
Protein, kg/d & 1.26 & 1.31 & 1.30 & 1.25 & 0.04 & 0.06 \\
Lactose, kg/d & 2.06 & 2.09 & 2.11 & 2.02 & 0.07 & 0.24 \\
3.5\% FCM, kg/d & 38.6 & 39.3 & 39.8 & 38.3 & 1.31 & 0.52 \\
Fat:protein & 0.94 & 0.91 & 0.96 & 0.96 & 0.06 & 0.64 \\
MUN, mg/dL & 15.39 & 15.83 & 15.42 & 15.73 & 0.58 & 0.48 \\
\hline
\end{tabular}

${ }^{1}$ The control diet (CON) contained no supplemental vitamins; the biotin diet (BIO) contained $0.87 \mathrm{mg}$ of supplemental biotin per kilogram of DM; the pantothenic acid diet (PAN) contained $21 \mathrm{mg}$ of supplemental pantothenic acid per kilogram of DM; and the biotin + pantothenic acid diet $(\mathrm{BIO}+\mathrm{PAN})$ contained $0.87 \mathrm{mg}$ of supplemental biotin and $21 \mathrm{mg}$ of supplemental pantothenic acid per kilogram of DM.

the first possibility could be discarded. Plasma concentration of ABS for control cows (Figure 1) in this study was greater than in previous studies (Table 3). Based on this observation, biotin would have not been limiting in this study, and therefore we did not observe a response in milk yield when biotin was supplemented.

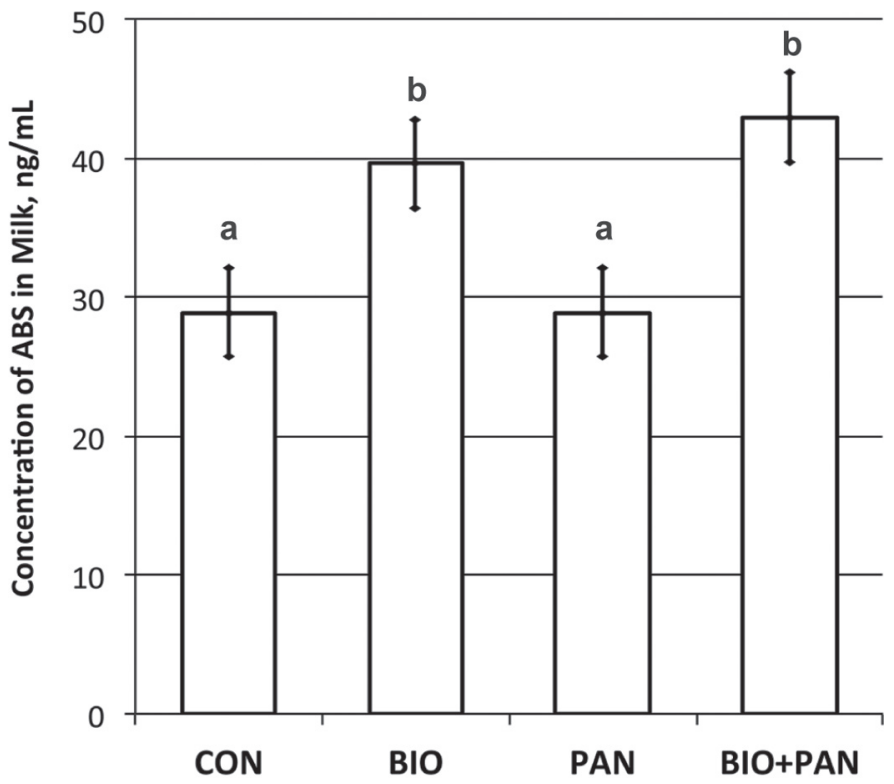

Figure 2. Concentration of avidin-binding substances (ABS) in skim milk of lactating dairy cows fed a control diet (CON), a diet supplemented with $0.87 \mathrm{mg}$ of biotin per kilogram of DM (BIO), a diet supplemented with $21 \mathrm{mg}$ of pantothenic acid per kilogram of DM (PAN), or a diet supplemented with $0.87 \mathrm{mg}$ of biotin and $21 \mathrm{mg}$ of pantothenic acid per kilogram of DM $(\mathrm{BIO}+\mathrm{PAN})$. Columns with different letters $(\mathrm{a}, \mathrm{b})$ are statistically different $(P<0.05)$. Error bars indicate the standard error of the mean $(\mathrm{SEM}=3.2 \mathrm{ng} / \mathrm{mL})$. 
Table 3. Concentration of avidin-binding substances in plasma (ng/ $\mathrm{mL})$ and milk $(\mathrm{ng} / \mathrm{mL})$ of cows supplemented with 0 or $20 \mathrm{mg} / \mathrm{d}$ of biotin

\begin{tabular}{lccccrr}
\hline & \multicolumn{2}{c}{ Plasma } & & \multicolumn{2}{c}{ Milk } \\
\cline { 2 - 3 } \cline { 5 - 6 } Item & Control & Biotin & & Control & Biotin \\
\hline Zimmerly and Weiss (2001) & 0.67 & 2.05 & & 22.6 & 69.8 \\
Rosendo et al. (2004) & 1.05 & 2.29 & & 94.2 & 258.9 \\
Ferreira et al. (2007) & 1.05 & 1.90 & & 35.5 & 123.2 \\
Ferreira and Weiss (2007) & 0.85 & 1.21 & & 26.8 & 80.4 \\
\hline
\end{tabular}

${ }^{1}$ Rosendo et al. (2004) supplemented $30 \mathrm{mg} / \mathrm{d}$ of biotin.

Little is known about biotin metabolism in ruminants. The concentration of ABS in milk is substantially higher than in plasma (Table 3), implying that biotin is transported against gradient in the mammary gland. Therefore, a biotin transport mechanism would likely exist at the mammary gland of bovine species, as it exists in human mammary cells (Vadlapudi et al., 2013). A biotin transporter mechanism also exists in kidneys to ensure biotin reabsorption (Balamurugan et al., 2005). Biotin uptake was increased under biotindeficient conditions in human renal cells (Balamurugan et al., 2005), reflecting the role of the kidney in sustaining biotin homeostasis under biotin-deficient conditions. Frigg et al. (1993) reported that the elimination half-life of biotin in yearling heifers is fast (i.e., less than $9 \mathrm{~h}$ ) and independent of biotin supplementation, and they concluded that the clearance of biotin was not affected by biotin supplementation. Reasons for the similar ABS concentration in plasma for control and biotin-supplemented cows in our study are unclear.

Biotin and pantothenic acid are absorbed through the same mechanisms in nonruminant species (Said and Redha, 1987; Said et al., 1988; Said and Derweesh, 1991). This mechanism involves a sodium-dependent transporter in the epithelium of the gastrointestinal tract. This transporter shares a high degree of sequence homology in nonruminant species (Ghosal et al., 2013), but to our knowledge its expression has not been determined for ruminant species.

We hypothesized that pantothenic acid inhibits the beneficial effects of biotin supplementation on milk yield by lactating dairy cows. Given that biotin and pantothenic acid are absorbed through the same transporter, the absorption of biotin was diminished with elevated doses of pantothenic acid (Chatterjee et al., 1999; Chirapu et al., 2013). Chatterjee et al. (1999) showed that the uptake of biotin was inhibited when cells containing transfected intestinal SMVT from rats were incubated with pantothenic acid. In this study cows supplemented with pantothenic acid had similar concentrations of ABS in both plasma and milk to control cows (Figures 1 and 2). In addition to this, the concentration of ABS in either plasma or milk (Figures 1 and 2) of cows supplemented with both vitamins did not differ from those of cows supplemented with biotin alone. These observations suggest that pantothenic acid did not affect the absorption of biotin.

Weak acids would be best absorbed at $\mathrm{pH}$ values below their $\mathrm{p} K_{\mathrm{a}}$ (Charman et al., 1997). Because it has acidic properties, with a $\mathrm{p} K_{\mathrm{a}}$ of 4.65 (Said et al., 1994), biotin should typically be present in its ionized form in the rumen and intestines. Consequently, in theory biotin transport by passive diffusion into the cells of the gastrointestinal tract should be minimum. One observation in our study was the low fat concentration in milk (Table 2), which was not observed in previous studies (Zimmerly and Weiss, 2001; Majee et al., 2003; Rosendo et al., 2004). Milk fat depression is likely related to diminished ruminal $\mathrm{pH}$ (Bauman and Griinari, 2001). Although speculative, if ruminal $\mathrm{pH}$ was decreased closer to the $\mathrm{p} K_{\mathrm{a}}$ of biotin in this study, then biotin absorption through passive diffusion in the rumen may have been increased (Charman et al., 1997), explaining the high basal ABS concentrations in plasma and maybe also the lack of interaction between biotin and pantothenic acid.

\section{CONCLUSIONS}

Pantothenic acid did not affect the concentrations of ABS in plasma and milk, therefore suggesting that increasing dietary supply of pantothenic acid did not inhibit biotin absorption. Based on this and previous observations, it is unclear what is the mechanism by which biotin supplementation typically increases milk yield, and the factors that affect this response. To increase this knowledge, future studies should evaluate the mechanism for biotin absorption (i.e., biotin transporters in the gastrointestinal tract), specifically the existence of a sodium-dependent transporter, such as SMVT.

\section{ACKNOWLEDGMENTS}

We are grateful to the students Kristina Anderson (Department of Agricultural and Applied Economics), Coty Goodwin (Department of Crop and Soil Environmental Sciences), Nicole Hardy (Department of Dairy Science), and Lauren Ruben (Department of Dairy Science, Virginia Polytechnic Institute and State University, Blacksburg) for their help feeding the animals. We are also grateful to DSM Nutritional Products for providing the biotin and the pantothenic acid used in the study. This project was supported, in part, by USDA-National Institute of Food and Agriculture Hatch Project VA-160025 and USDA-National 
Institute of Food and Agriculture Multistate Project VA-136291 (NC-2042, Management Systems to Improve the Economic and Environmental Sustainability of Dairy Enterprises).

\section{REFERENCES}

Balamurugan, K., N. D. Vaziri, and H. M. Said. 2005. Biotin uptake by human proximal tubular epithelial cells: Cellular and molecular aspects. Am. J. Physiol. Renal Physiol. 288:F823-F831.

Bauman, D. E., and J. M. Griinari. 2001. Regulation of nutritional manipulation of milk fat: Low-fat milk syndrome. Livest. Prod. Sci. 70:15-29.

Charman, W. N., C. J. H. Porter, S. Mithani, and J. B. Dressman. 1997. Physicochemical and physiological mechanisms for the effects of food on drug absorption: the role of lipids and $\mathrm{pH}$. J. Pharm. Sci. 86:269-282.

Chatterjee, N. S., C. K. Kumar, A. Ortiz, S. A. Rubin, and H. M. Said. 1999. Molecular mechanism of the intestinal biotin transport process. Am. J. Physiol. 277:C605-C613.

Chirapu, S. R., C. J. Rotter, E. L. Miller, M. V. Varma, R. L. Dow, and M. G. Finn. 2013. High specificity in response of the sodiumdependent multivitamin transporter to derivatives of pantothenic acid. Curr. Top. Med. Chem. 13:837-842.

Ferreira, G., and W. P. Weiss. 2007. Effect of biotin on activity and gene expression of biotin-dependent carboxylases in the liver of dairy cows. J. Dairy Sci. 90:1460-1466.

Ferreira, G., L. B. Willett, and W. P. Weiss. 2007. Changes in measures of biotin status do not reflect milk yield responses when dairy cows are fed supplemental biotin. J. Dairy Sci. 90:1452-1459.

Fitzgerald, T., B. W. Norton, R. Elliott, H. Podlich, and O. L. Svendsen. 2000. The influence of long-term supplementation with biotin on the prevention of lameness in pasture fed dairy cows. J. Dairy Sci. 83:338-344.

Frigg, M., O. C. Straub, and D. Hartmann. 1993. The bioavailability of supplemental biotin in cattle. Int. J. Vitam. Nutr. Res. 63:122-128.

Ghosal, A., N. Lambrecht, S. B. Subramanya, R. Kapadia, and H. M. Said. 2013. Conditional knockout of the Slc5a6 gene in mouse intestine impair biotin absorption. Am. J. Physiol. Gastrointest. Liver Physiol. 304:G64-G71.

Hall, M. B. 2009. Determination of starch, including maltooligosaccharides, in animal feeds: Comparison of methods and a method recommended for AOAC collaborative study. J. AOAC Int. $92: 42-49$
Majee, D. N., E. C. Schwab, S. J. Bertics, W. M. Seymour, and R. D. Shaver. 2003. Lactation performance by dairy cows fed supplemental biotin and B-vitamin blend. J. Dairy Sci. 86:2106-2112.

Midla, L. T., K. H. Hoblet, W. P. Weiss, and M. L. Moeschberger. 1998. Supplemental dietary biotin for prevention of lesions associated with aseptic subclinical laminitis (pododermatitis aseptica diffusa) in primiparous cows. Am. J. Vet. Res. 59:733-738.

NRC. 2001. Nutrient Requirements of Dairy Cattle. 7th ed. Natl. Acad. Press, Washington, DC.

Prasad, P. D., H. Wang, R. Kekuda, T. Fujita, Y. J. Fei, L. D. Devoe F. H. Leibach, and V. Ganapathy. 1998. Cloning and functional expression of a cDNA encoding mammalian sodium-dependent vitamin transporter mediating the uptake of pantothenate, biotin, and lipoate. J. Biol. Chem. 273:7501-7506.

Rosendo, O., C. R. Staples, L. R. McDowell, R. McMahon, L. Badinga, F. G. Martin, J. F. Shearer, W. M. Seymour, and N. S. Wilkinson. 2004. Effects of biotin supplementation on peripartum performance and metabolites of Holstein cows. J. Dairy Sci. $87: 2535-2545$

Said, H. M. 1999. Cellular uptake of biotin: Mechanisms and regulation. J. Nutr. 129:490S-493S.

Said, H. M., and I. Derweesh. 1991. Carrier-mediated mechanism for biotin transport in rabbit intestine: Studies with brush-border membrane vesicles. Am. J. Physiol. 261:R94-R97.

Said, H. M., T. Y. Ma, and V. S. Kamanna. 1994. Uptake of biotin by human hepatoma cell line, Hep G2: A carrier-mediated process similar to that of normal liver. J. Cell. Physiol. 161:483-489.

Said, H. M., D. M. Mock, and J. C. Collins. 1989. Regulation of intestinal biotin transport in the rat: Effect of biotin deficiency and supplementation. Am. J. Physiol. 256:G306-G311.

Said, H. M., and R. Redha. 1987. A carrier-mediated system for transport of biotin in rat intestine in vitro. Am. J. Physiol. 252:G52G55.

Said, H. M., R. Redha, and W. Nylander. 1987. A carrier-mediated, $\mathrm{Na}+$ gradient dependent transport for biotin in human intestinal brush-border membrane vesicles. Am. J. Physiol. 253:G631G636.

Said, H. M., R. Redha, and W. Nylander. 1988. Biotin transport in the human intestine: Site of maximum transport and effect of $\mathrm{pH}$ Gastroenterology 95:1312-1317.

Vadlapudi, A. D., R. K. Vadlapatla, D. Pal, and A. K. Mitra. 2013. Biotin uptake by T47D breast cancer cells: Functional and molecular evidence of sodium-dependent multivitamin transporter (SMVT). Int. J. Pharm. 441:535-543.

Zimmerly, C. A., and W. P. Weiss. 2001. Effects of supplemental dietary biotin on performance of Holstein cows during early lactation. J. Dairy Sci. 84:498-506. 